\title{
EFEITO DE ESPACAMENTO E DENSIDADE DE SEMEADURA SOBRE A PRODUTIVIDADE E OS COMPONENTES DE PRODUÇÃO DA CULTIVAR DE ARROZ BRSMG CONAI
}

\author{
Effect of sowing spacing and density on yield and production components of rice \\ cultivar BRSMG Conai
}

\author{
João Afonso de Carvalhor ${ }^{1}$, Antônio Alves Soares ${ }^{2}$, Moizés de Sousa Reis ${ }^{3}$
}

\begin{abstract}
RESUMO
Objetivou-se com este trabalho avaliar a resposta da nova cultivar de arroz superprecoce de terras altas BRSMG Conai (Oryza sativa L.) ao efeito dos espaçamentos entre linhas $(20,30 \mathrm{e} 40 \mathrm{~cm})$ e das densidades de semeadura $\left(50,80\right.$ e 110 sementes $\left.\mathrm{m}^{-1}\right)$. Foram conduzidos três experimentos: Machado ( $1^{\mathrm{a}}$ e $2^{\mathrm{a}}$ épocas) e Lavras, MG, em 2004/05. Empregou-se o delineamento experimental de blocos casualizados, no esquema fatorial $3 \times 3$, com três repetições. Foram avaliados os componentes de produção de grãos: número de panículas $\mathrm{m}^{-2}$, número de grãos por panícula, porcentagem de grãos cheios e massa de 100 grãos e a produtividade de grãos. Os resultados mostram forte influência de espaçamento e densidade sobre o número de panículas, número de grãos por panícula e produtividade de grãos. Apenas espaçamento exerce pouca influência sobre a porcentagem de grãos cheios e massa de 100 grãos. Já a densidade somente não exerce qualquer influência sobre a porcentagem de grãos cheios, porém, exerce forte influência sobre a massa de 100 grãos. Os componentes da produção mais influenciados pelo espaçamento e densidade são o número de panículas $\mathrm{m}^{-2}$ e o número de grãos por panícula. Em síntese, houve a maximização da produtividade de grãos, para a cultivar BRSMG Conai, no espaçamento de $30 \mathrm{~cm}$ entrelinhas, independente da densidade de semeadura. Quanto à densidade, 80 sementes $\mathrm{m}^{-1}$ foi a que mais contribuiu para a produtividade.
\end{abstract}

Termos para indexação: Oryza sativa, arroz de terras altas, estande de plantas.

\section{ABSTRACT}

The objective of this work was to evaluate the response of the new upland super precocious rice cultivar BRSMG Conai (Oryza sativa $L$.$) , to the effect of interrow spacing (20,30$ and $40 \mathrm{~cm})$ and sowing density $\left(50,80 \mathrm{e} 110 \mathrm{seeds} \mathrm{m}^{-1}\right)$. Three experiments were conducted: Machado ( $1^{\text {st }}$ and $2^{\text {nd }}$ times) and Lavras, MG, Brazil, in 2004/05. The experimental design in randomized block in the factorial scheme $3 \times 3$ with three replicates was employed. The production components number of panicles $\mathrm{m}^{-2}$, number of grains per panicle, $\%$ of filled grains, mass of 100 grains and grain yield were evaluated. The results showed a strong influence of space-density on the number of panicles, number of grains per panicle and yield. Only spacing exerts a little influence on \% of filled grains and mass of 100 grains. Density only does exerts no influence on \% of filled grains, but it does exert a strong influence on the mass of 100 grains. The production components most influenced by spacing-density are the number of panicles $\mathrm{m}^{-2}$ and the number of grains per panicle. In short, there was a maximization of grain yield in cultivar BRSMG Conai, at $30 \mathrm{~cm}$ interrow spacing, regardless of sowing density. As regards density, that of 80 seeds $\mathrm{m}^{-1}$ was the one which most contributed to yield.

Index terms: Oryza sativa, upland rice, plants of stands.

(Recebido em 13 de julho de 2006 e aprovado em 18 de janeiro de 2007)

\section{INTRODUÇÃO}

A determinação do espaçamento e da densidade de semeadura que proporcionem o melhor arranjo entre as plantas, de modo a maximizar a produtividade de grãos e outros componentes da produção, é preocupação antiga dos agricultores. Muitos são os trabalhos de pesquisa que visam identificar os melhores espaçamentos e densidades para as principais espécies de importância econômica (milho, soja e arroz, entre outras) e os que existem, nem sempre são consensuais para as diversas cultivares e ambientes.
Combinações de espaçamento e densidade ótima não existe, mas sim, aquela próxima do ideal, pois são muitos os fatores que interagem com a planta de modo a permitir a máxima expressão gênica da cultivar. Portanto, não se pode generalizar um ótimo para todas as cultivares de arroz, em face dos diferentes efeitos ambientais e capacidade de perfilhamento.

Em arroz de terras altas, tem-se recomendado espaçamento na faixa de 40 a $50 \mathrm{~cm}$ entrelinhas e densidade de semeadura de 60 a 70 sementes, por metro (BRESEGHELLO, 1998; SOARES, 2005). Recentemente, a

\footnotetext{
${ }^{1}$ Engenheiro Agrônomo, Mestre em Fitotecnia - Departamento de Culturas Anuais - Escola Agrotécnica Federal de Machado/EAF Machado - Rodovia Machado, Paraguaçu, Km 03, Santo Antônio - Cx. P. 49 - 37750-000 - Machado, MG - jafocarvalho@yahoo.com.br ${ }^{2}$ Engenheiro Agrônomo, Doutor - Departamento de Agricultura/DAG - Universidade Federal de Lavras/UFLA - Cx. P. 3037 - $37200-000$ - Lavras, MG aasoares@ufla.br

${ }^{3}$ Engenheiro Agrônomo, Doutor, Pesquisador - EPAMIG/CTSM - Cx. P. 176 - 37200-000 - Lavras, MG - moireis@hotmail.com
} 
pesquisa tem lançado um grande número de cultivares com diferentes portes, ciclos e tipos de planta, entre outras características. Entre elas, destacam-se as cultivares modernas de ciclo superprecoce, folhas eretas e altura intermediária. Novos ajustamentos de população de plantas para as diferentes cultivares fazem-se necessários.

Objetivou-se, neste trabalho, determinar, para a nova cultivar de arroz de terras altas BRSMG Conai, de ciclo superprecoce (inferior a 110 dias), o espaçamento e a densidade de semeadura que maximizem a produtividade de grãos, e o efeito das mesmas sobre os componentes de produção de grãos, altura de planta, floração média e incidência de doenças.

Pesquisou-se encontrar o arranjo ideal de plantas para a nova cultivar superprecoce de terras altas BRSMG Conai, combinando diferentes espaçamentos e densidades de semeadura, no sistema de cultivo convencional.

\section{MATERIAL E MÉTODOS}

Os experimentos foram instalados em 2004/2005 em duas épocas em Machado, MG, e em uma época em Lavras, $\mathrm{MG}$, constituindo três ambientes. $\mathrm{O}$ primeiro, foi instalado na fazenda da Escola Agrotécnica Federal de Machado (EAFMachado), o segundo, em área do Campus da Universidade Federal de Lavras-UFLA. O terceiro foi implantado, novamente, na fazenda da EAF-Machado. Machado localizase na latitude de $21^{\circ} 40^{\prime} \mathrm{S}$ e longitude de $45^{\circ} 55^{\prime} \mathrm{W}$. O nível altimétrico para o local é de 873 metros. O solo é do tipo argissolo vermelho escuro. Lavras situa-se a $918 \mathrm{~m}$ de altitude, $21^{\circ} 14^{\prime} \mathrm{S}$ de latitude e $45^{\circ} 00^{\prime} \mathrm{W}$ de longitude. $\mathrm{O}$ solo do local é classificado como argissolo vermelho-amarelo distroférrico típico. Os dois municípios possuem características topoclimáticas de montanha, com clima temperado chuvoso mesotérmico (Cwa) (ANTUNES, 1986). As precipitações pluviais médias são de 1300 a $1400 \mathrm{~mm}$ por ano, sendo que 70 a $80 \%$ concentram-se nos meses de outubro a março.

O delineamento experimental utilizado foi o de blocos casualizados, no esquema fatorial 3x3, com três repetições. Avaliou-se a cultivar superprecoce de arroz de terras altas BRSMG Conai, em três espaçamentos (20, 30 e $40 \mathrm{~cm}$ ) entrelinhas e três densidades de semeadura $(50,80$ e $110 \mathrm{sem} \mathrm{m}^{-1}$ ). As parcelas mediram $5 \mathrm{~m}$ de comprimento por 2,4 $\mathrm{m}$ de largura e apresentaram número de linhas variáveis (12, 8, 6 linhas), de acordo com o espaçamento. Constituíram as bordaduras, as duas linhas laterais e $0,5 \mathrm{~m}$ nas extremidades das três linhas centrais. Assim, as áreas úteis foram de $8,00 \mathrm{~m}^{2}, 7,20 \mathrm{~m}^{2}$, e $6,40 \mathrm{~m}^{2}$, para os espaçamentos de 20,30 e $40 \mathrm{~cm}$, respectivamente.

A adubação de semeadura constou de $350 \mathrm{~kg} \mathrm{ha}^{-1}$ da fórmula 04-30-16 + Zn (0,5) e em cobertura $48 \mathrm{~kg} \mathrm{ha}^{-1} \mathrm{de}$
$\mathrm{N}$ (uréia), aos 35 dias após a emergência (DAE). Os experimentos foram irrigados por aspersão sempre que houve necessidade, mantendo o solo sempre com umidade. Os tratos culturais realizados nos experimentos foram aqueles indicados para o cultivo de arroz de terras altas. Procedeu-se à colheita quando os grãos estavam com umidade de $20-23 \%$, sendo posteriormente secados até $13 \%$ de umidade.

Os componentes de produção de grãos avaliados, de acordo com Soares (2005) foram: porcentagem de grãos cheios, massa de 100 grãos (g), número de panículas $\mathrm{m}^{-2} \mathrm{e}$ número de grãos por panícula. Avaliou-se também, a produtividade de grãos $\left(\mathrm{kg} \mathrm{ha}^{-1}\right)$.

Os dados, após os testes de normalidade e homocedasticidade, foram submetidos à análise de variância conjunta, envolvendo os três ambientes experimentais. Para as análises estatísticas, utilizou-se o software "SISVAR" (FERREIRA, 2003). Quando as variáveis eram de natureza qualitativa (ambiente e espaçamento) o teste de média utilizado foi o de Scott-Knott, a 5\% de probabilidade, porém quando eram de natureza quantitativa (densidade), utilizouse análise de regressão.

\section{RESULTADOS E DISCUSSÃO}

O resumo da análise de variância conjunta dos experimentos em Machado ( $1^{\mathrm{a}}$ e $2^{\mathrm{a}}$ épocas) e Lavras apresentam-se na Tabela 1.

Para porcentual de grãos cheios, a significância ocorreu apenas em relação a variável ambiente. Essa é uma característica das mais importantes para definição da produtividade de grãos. Para Soares (2001), é também a mais vulnerável por variar de acordo com as condições climáticas, níveis de nutrientes e incidência de doenças e pragas. A média do porcentual de grãos cheios foi semelhante em Machado ( $1^{\mathrm{a}}$ e $2^{\mathrm{a}}$ época) e inferior no experimento de Lavras, onde, ocorreu maior incidência de doenças como brusone e mancha de grãos (Tabela 2).

Para massa de 100 grãos (Tabela 1), obteve-se significância estatística para efeito de ambiente, densidade e interação espaçamento e densidade. O efeito de ambiente sobre a massa de 100 grãos verifica-se pela Tabela 2 . Notase que a média por ambiente foi maior em Machado $1^{\mathrm{a}}$ época $(3,24 \mathrm{~g})$, superando a de Machado $2^{\mathrm{a}}$ época $(3,07 \mathrm{~g})$ que, por sua vez, superou a de Lavras (2,51 g).

$O$ resultado do desdobramento da interação espaçamento $\mathrm{x}$ densidade $\left(\mathrm{E}^{*} \mathrm{D}\right)$ para massa de 100 grãos como observa-se na Tabela 3 onde não ocorreu efeito do espaçamento para nenhum nível de densidade. Resultados esses que corroboram os trabalhos de Crusciol et al. (2003) e com os de Santos et al. (2002). Neles os autores 
Tabela 1 - Análise de variância conjunta dos experimentos de Machado ( $1^{\mathrm{a}}$ e $2^{\mathrm{a}}$ épocas $)$ e Lavras para as características: \% de grãos cheios por panícula (GC); massa de 100 grãos (M100), $\mathrm{n}^{\circ}$ de panículas $\mathrm{m}^{-2}(\mathrm{NP}) ; \mathrm{n}^{\mathrm{o}}$ de grãos por panícula (NG) e produtividade de grãos (PROD).

\begin{tabular}{|c|c|c|c|c|c|c|}
\hline \multirow{2}{*}{ Fontes de variação } & \multirow[b]{2}{*}{ GL } & \multicolumn{5}{|c|}{ QM } \\
\hline & & GC & M100 & NP & NG & PROD \\
\hline Blocos: (Ambiente) & 6 & $6,473^{\mathrm{NS}}$ & $0,012^{\mathrm{NS}}$ & $1913,91 * *$ & $113,16^{\mathrm{NS}}$ & $208602,65^{\mathrm{NS}}$ \\
\hline Espaçamentos (E) & 2 & $4,709^{\mathrm{NS}}$ & $0,005^{\mathrm{NS}}$ & $40315,42 *$ & $1660,45^{* *}$ & $3030718,05^{* *}$ \\
\hline Densidades (D) & 2 & $2,542^{\mathrm{NS}}$ & $0,035 *$ & $28292,01 * *$ & $2944,48 * *$ & $630293,69 *$ \\
\hline Ambientes (A) & 2 & $18,025^{*}$ & $3,951 * *$ & $36808,94 * *$ & $5320,16^{* *}$ & $2514935,05^{* *}$ \\
\hline $\mathrm{E} * \mathrm{D}$ & 4 & $1,828^{\mathrm{NS}}$ & $0,033 *$ & $3855,53^{*}$ & $226,76^{*}$ & $848794,26 * *$ \\
\hline $\mathrm{E} * \mathrm{~A}$ & 4 & $3,576^{\mathrm{NS}}$ & $0,017^{\mathrm{NS}}$ & $1771,12^{\mathrm{NS}}$ & $206,58^{\mathrm{NS}}$ & $820753,28 * *$ \\
\hline $\mathrm{D} * \mathrm{~A}$ & 4 & $2,114^{\mathrm{NS}}$ & $0,015^{\mathrm{NS}}$ & $3750,27 *$ & $100,88^{\mathrm{NS}}$ & $240645,45^{\mathrm{NS}}$ \\
\hline $\mathrm{E} * \mathrm{D} * \mathrm{~A}$ & 8 & $4,846^{\mathrm{NS}}$ & $0,013^{\mathrm{NS}}$ & $4289,93 * *$ & $598,08 * *$ & $521512,31 * *$ \\
\hline Erro & 48 & 6,473 & 0,011 & 1048,80 & 83,91 & 164938,53 \\
\hline $\mathrm{CV}(\%)$ & & 2,25 & 3,54 & 8,93 & 9,15 & 8,12 \\
\hline Média geral & & 94,3 & 2,94 & 362,57 & 100,12 & 5001,84 \\
\hline
\end{tabular}

*Significativo pelo teste $\mathrm{F}(\mathrm{p} \leq 0,05)$ e **Significativo pelo teste $\mathrm{F}(\mathrm{p} \leq 0,01)$; ${ }^{\mathrm{NS}}=$ Não significativo.

Tabela 2 - Médias para a variável ambiente, dos experimentos de Machado ( $1^{\mathrm{a}}$ e $2^{\mathrm{a}}$ épocas $)$ e Lavras; em função das características: percentual de grãos cheios (GC) e massa de 100 grãos (M100).

\begin{tabular}{lll}
\hline \multicolumn{1}{c}{ Ambientes experimentais } & \multicolumn{1}{c}{$\mathrm{GC}^{1}$} & $\mathrm{M}^{1} 00^{1}$ \\
\hline Ambiente 1 - Machado $1^{\mathrm{a}}$ época & $94,48 \mathrm{a}$ & $3,24 \mathrm{a}$ \\
Ambiente 2 - Lavras & $93,41 \mathrm{~b}$ & $2,51 \mathrm{c}$ \\
Ambiente 3 - Machado 2 época & $95,01 \mathrm{a}$ & $3,07 \mathrm{~b}$ \\
\hline Média geral & 94,30 & 2,94 \\
\hline
\end{tabular}

${ }^{1}$ Médias seguidas da mesma letra, nas colunas, não diferem entre si, pelo teste Scott-Knott para $\mathrm{p} \leq 0,05$.

Tabela 3 - Médias para massa de 100 grãos, em função de espaçamento dentro de densidade (E:D), cultivar BRSMG Conai, nos experimentos de Machado (1 $1^{\mathrm{a}}$ e $2^{\mathrm{a}}$ épocas) e Lavras. 2004/2005.

\begin{tabular}{|c|c|c|c|}
\hline \multirow[b]{2}{*}{ Densidades } & \multicolumn{3}{|c|}{ Espaçamento entre linhas em $\mathrm{cm}^{1}$} \\
\hline & 20 & 30 & 40 \\
\hline $\mathrm{D}_{50}$ & $2,85 \mathrm{a}$ & $2,94 \mathrm{a}$ & $2,89 \mathrm{a}$ \\
\hline $\mathrm{D}_{80}$ & $3,01 \mathrm{a}$ & $2,97 \mathrm{a}$ & $2,89 \mathrm{a}$ \\
\hline $\mathrm{D}_{110}$ & $2,92 \mathrm{a}$ & $2,94 \mathrm{a}$ & $3,01 \mathrm{a}$ \\
\hline
\end{tabular}

${ }^{1}$ As médias seguidas da mesma letra, nas linhas, não diferem entre si, pelo teste Scott-Knott para $\mathrm{p} \leq 0,05$.

observaram a mesma tendência, ou seja, ausência de significância estatística para efeito de espaçamentos.

Para Yoshida (1972), a massa de 100 grãos é uma característica genética, que depende principalmente do tamanho da casca da cultivar e da formação dos grãos durante a fase de maturação. Porém, deficiência hídrica, de nitrogênio, baixa radiação solar e incidência de brusone no período de floração, reduzem a massa de grãos.

No desdobramento de densidade dentro de espaçamento (D:E), para massa de 100 grãos, encontrouse uma relação linear e outra quadrática (Figura 1). Nessa figura, a equação de regressão Y1 (D: $\left.\mathrm{E}_{40}\right)$, mostrou-se linearmente positiva, à razão de 0,002 g para cada semente 
além de $50 \mathrm{~m}^{-1}$. Já a equação quadrática Y2 (D: $\left.\mathrm{E}_{20}\right)$ apresentou um coeficiente de regressão crescente da ordem de $0,0236 \mathrm{~g}$ por unidade de semente, até 84 sementes $\mathrm{m}^{-1}$; nesse ponto a massa de 100 grãos alcançou 3,01 g. A partir daí, à medida que a densidade aumenta, a massa de 100 grãos diminui à razão de 0,0001 grama, para cada semente.

Observa-se que a densidade de semeadura tem uma forte influência sobre massa de 100 grãos apesar dela ser uma característica genética estável e mais dependente do tamanho da casca. Contudo, o presente trabalho difere dos resultados de Santos et al. (2002) que não encontraram significância estatística para essa característica, em função da densidade de 50, 70 e 90 sementes $\mathrm{m}^{-1}$, para as cultivares Canastra e Confiança.

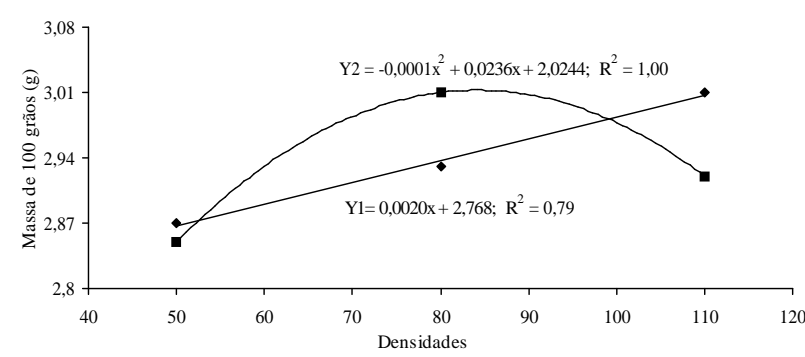

Figura 1 - Representação gráfica da equação de regressão para massa de 100 grãos (g), em função de D: $E_{20}$ e D: $E_{40}$.

Para número de panículas $\mathrm{m}^{-2}$ ocorreu significância para várias fontes de variação (Tabela 1), entretanto, estudou-se apenas a interação tripla espaçamento dentro de densidade e ambiente (E:D-A), cujo resultado está lançado na Tabela 4. Observa-se que, em apenas dois níveis de D-A ( $D_{50} A_{3}$ e $\left.D_{80} A_{2}\right)$ não houve efeito significativo de espaçamentos sobre o número de panículas $\mathrm{m}^{-2}$. Portanto, o espaçamento exerce importante efeito sobre o número de panículas $\mathrm{m}^{-2}$, independente da densidade e ambiente de cultivo. Mostra-se ainda na Tabela 4 que o espaçamento de $30 \mathrm{~cm}$ resultou no maior número de panículas $\mathrm{m}^{-2}$ (386). As densidades de semeadura que mais influenciaram o número de panículas $\mathrm{m}^{-2}$ foram 110 e $80 \mathrm{sem} \mathrm{m}^{-1}$ (383 e 380). Com esse resultado, pode-se inferir que o arranjo de $30 \mathrm{~cm}$ entrelinhas por $110 \mathrm{e} 80 \mathrm{sem} \mathrm{m}^{-1}$, independente do ambiente, são os tratamentos que proporcionaram o maior número de perfilhos produtivos. Resultados semelhantes foram encontrados por Crusciol et al. (2003), que também encontraram influência do espaçamento sobre o número de panículas $\mathrm{m}^{-2}\left(195,160\right.$ e $\left.132 \mathrm{~m}^{-2}\right)$, obtidas nos respectivos espaçamentos de 30,40 e $50 \mathrm{~cm}$ entrelinhas.

O desdobramento de densidade dentro de espaçamento-ambiente (D:E-A) para número de panículas $\mathrm{m}^{-2}$ resultou em equações de regressão lineares e quadráticas (Figura 2). Nas equações lineares Y1, Y2 e Y4, a densidade de semeadura influenciou positivamente na quantidade de panículas $\mathrm{m}^{-2}$. O número delas aumentou linearmente à razão de 1,$38 ; 2,5$ e 1,16 panículas $\mathrm{m}^{-2}$, para cada semente além de $50 \mathrm{~m}^{-1}$. Esses resultados são condizentes com os encontrados por Santos et al. (2002)

Tabela 4 - Médias dos desdobramentos de espaçamento dentro de densidade-ambiente (E:D-A) para número de panículas $\mathrm{m}^{-2}(\mathrm{NP})$, número de grãos por panícula (NG) e produtividade de grãos (PROD) nos experimentos em Machado $\left(1^{\mathrm{a}}\right.$ e $2^{\mathrm{a}}$ épocas) e Lavras. 2004/2005.

\begin{tabular}{|c|c|c|c|c|c|c|c|c|c|c|c|c|c|c|c|}
\hline \multirow[b]{3}{*}{ D-A } & \multicolumn{5}{|c|}{ Número de panícula $\mathrm{m}^{-2}$} & \multicolumn{5}{|c|}{ Número de grãos por panícula } & \multicolumn{5}{|c|}{ Produtividade de grãos } \\
\hline & \multicolumn{5}{|c|}{ Espaçamentos ${ }^{1}$} & \multicolumn{5}{|c|}{ Espaçamentos $^{1}$} & \multicolumn{5}{|c|}{ Espaçamentos $^{1}$} \\
\hline & 20 & 30 & 40 & Méd & $\mathrm{s} \mathrm{p} / \mathrm{D}^{2}$ & 20 & 30 & 40 & Média & $\mathrm{p} / \mathrm{D}^{2}$ & 20 & 30 & 40 & Média & $\mathrm{s} p / \mathrm{D}^{2}$ \\
\hline $50-1$ & $372 \mathrm{a}$ & $286 \mathrm{~b}$ & $299 \mathrm{~b}$ & 319 & \multirow{3}{*}{325} & $113 \mathrm{a}$ & $94 \mathrm{~b}$ & $107 \mathrm{a}$ & 105 & \multirow{3}{*}{112} & 5471 a & $5254 \mathrm{a}$ & $4587 \mathrm{~b}$ & 5104 & \multirow{3}{*}{4840} \\
\hline $50-2$ & $359 \mathrm{~b}$ & $452 \mathrm{a}$ & $333 \mathrm{~b}$ & 381 & & $124 \mathrm{~b}$ & $145 \mathrm{a}$ & $128 \mathrm{~b}$ & 132 & & $4635 a$ & 5195 a & 4966 a & 4932 & \\
\hline $50-3$ & $284 \mathrm{a}$ & 298 a & $244 \mathrm{a}$ & 275 & & $89 a$ & $106 \mathrm{a}$ & $101 \mathrm{a}$ & 99 & & 4847 a & 4426 a & $4182 \mathrm{a}$ & 4485 & \\
\hline $80-1$ & $366 \mathrm{~b}$ & $430 \mathrm{a}$ & $345 \mathrm{~b}$ & 380 & \multirow{3}{*}{380} & $71 \mathrm{c}$ & $110 \mathrm{a}$ & $94 \mathrm{~b}$ & 92 & \multirow{3}{*}{97} & $4675 \mathrm{c}$ & $6325 \mathrm{a}$ & $5386 \mathrm{~b}$ & 5462 & \multirow{3}{*}{5144} \\
\hline $80-2$ & $416 \mathrm{a}$ & $444 \mathrm{a}$ & $410 \mathrm{a}$ & 423 & & $97 \mathrm{~b}$ & $108 \mathrm{~b}$ & $128 \mathrm{a}$ & 111 & & 4942 a & 5245 a & 5019 a & 5069 & \\
\hline $80-3$ & $372 \mathrm{a}$ & $358 \mathrm{a}$ & $280 \mathrm{~b}$ & 337 & & $81 \mathrm{a}$ & $87 \mathrm{a}$ & $95 \mathrm{a}$ & 88 & & $4884 \mathrm{a}$ & $5161 \mathrm{a}$ & 4659 a & 4901 & \\
\hline $110-1$ & $411 \mathrm{a}$ & $427 \mathrm{a}$ & $302 \mathrm{~b}$ & 380 & \multirow{3}{*}{383} & $62 b$ & $104 \mathrm{a}$ & $95 \mathrm{a}$ & 87 & \multirow{3}{*}{91} & $4356 \mathrm{~b}$ & $6353 \mathrm{a}$ & $5668 \mathrm{~b}$ & 5459 & \multirow{3}{*}{5021} \\
\hline $110-2$ & $441 \mathrm{a}$ & $411 \mathrm{a}$ & $342 \mathrm{~b}$ & 398 & & $96 \mathrm{~b}$ & $101 \mathrm{~b}$ & $118 \mathrm{a}$ & 105 & & $4263 \mathrm{a}$ & $5640 \mathrm{a}$ & $4310 \mathrm{a}$ & 4738 & \\
\hline $110-3$ & $434 \mathrm{a}$ & $368 \mathrm{~b}$ & $307 \mathrm{c}$ & 370 & & $86 \mathrm{a}$ & $84 \mathrm{a}$ & $77 \mathrm{a}$ & 82 & & $4851 \mathrm{a}$ & $4874 \mathrm{a}$ & 4876 a & 4867 & \\
\hline$M \backslash E^{3}$ & 384 & 386 & 318 & 363 & - & 91 & 104 & 105 & 100 & - & 4769 & 5386 & 4850 & 5002 & - \\
\hline
\end{tabular}

${ }^{1}$ Médias para espaçamentos seguidas da mesma letra, nas linhas, não diferem entre si, pelo teste Scott-Knott (p $\left.\leq 0,05\right)$.

${ }^{2}$ Médias para densidade.

${ }^{3}$ Médias para espaçamento. 
em Lavras para as cultivares Canastra e Confiança que também verificaram uma relação linear para o número de panículas $\mathrm{m}^{-2}$, porém com um menor coeficiente de regressão linear $\left(0,95 \mathrm{~m}^{-2}\right)$.

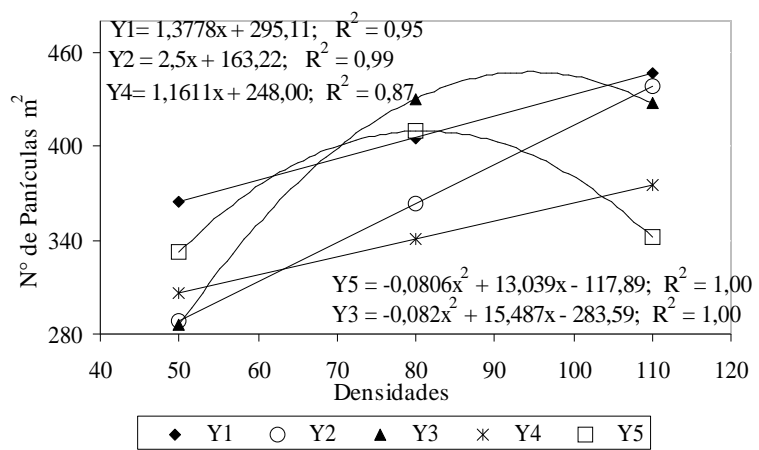

Figura 2 - Representação gráfica da equação de regressão, para $\mathrm{n}^{\circ}$ de panículas $\mathrm{m}^{-2}$, em função de $\mathrm{D}: \mathrm{E}_{20} \mathrm{~A}_{2} ; \mathrm{D}: \mathrm{E}_{20} \mathrm{~A}_{3}$; $\mathrm{D}: \mathrm{E}_{30} \mathrm{~A}_{1} ; \mathrm{D}: \mathrm{E}_{30} \mathrm{~A}_{3} ; \mathrm{D}: \mathrm{E}_{40} \mathrm{~A}_{2}$.

Já, nas equações quadráticas Y3 e Y5, o número de panículas $\mathrm{m}^{-2}$ respondeu positivamente à densidade de semeadura até o ponto máximo de 94 e 81 sem m$^{-1}$, respectivamente. Nesses pontos, o número de panículas também foram máximas (447) e (410). A partir daí, as maiores densidades desfavoreceram o número de panículas por área. Resultados que corroboram com os obtidos por Guimarães \& Stone (2003) que também encontraram resposta quadrática para o efeito da densidade $70 \mathrm{sem} \mathrm{m}^{-1}$ sobre o número de panículas $\mathrm{m}^{-2}$, ao trabalharem com duas cultivares: BRS Primavera e Canastra.

$\mathrm{Na}$ análise conjunta para o número de grãos por panícula (Tabela 1), encontrou-se significância para várias fontes de variação, contudo desdobrou-se apenas a interação tripla $\mathrm{E}^{*} \mathrm{D} * \mathrm{~A}$, cujo resultado apresenta-se na Tabela 4. Notou-se, no desdobramento E:D-A, significância para espaçamento em seis das nove combinações de densidade-ambiente. No ambiente 3 (Machado $2^{a}$ época), não houve efeito de espaçamento sobre o número de grãos por panícula, independente da densidade. Pode-se inferir que a semeadura tardia atenua o efeito de espaçamento sobre o número de grãos por panícula. Na Tabela 4 verifica-se ainda o arranjo que proporcionou o maior número de grãos por panícula (30 e $40 \mathrm{~cm}$ entrelinhas por 50 sementes $\mathrm{m}^{-1}$ ). Resultados semelhantes para espaçamento foram encontrados por Guimarães et al. (2003) que, ao avaliarem espaçamentos para as novas cultivares de arroz de terras altas, obtiveram maior número de grãos por panícula no espaçamento de 30 $\mathrm{cm}$ entre linhas, independente da densidade. Já, Santos et al. (2002) encontraram em Lavras, para as cultivares Canastra e Confiança, as mesmas tendências, ou seja, o número de grãos foi maior em espaçamentos maiores (30 e $40 \mathrm{~cm})$ e menor em espaçamento menor $(20 \mathrm{~cm})$. Essa Tendência observou-se também para o efeito de densidade, ou seja, maior número de grãos por panícula, na densidade de 50 sementes $\mathrm{m}^{-1}$.

Porém, quando se desdobrou a densidade dentro de espaçamento-ambiente (D:E-A), encontrou-se, para número de grãos por panícula, equações de regressão lineares (Figura 3). Em todas as equações lineares (Y1, Y2, Y3, Y4 e Y5), os coeficientes de regressão foram negativos. Resultados que condizem com a afirmação de Soares (2001), onde a densidade de semeadura crescente correlaciona-se negativamente com o número de grãos por panícula, já que o maior número de plantas por área tende a reduzir o tamanho das panículas. Porém, Guimarães \& Stone (2003) encontraram coeficiente de regressão linear positivo para número de grãos por panícula, para a cultivar BRS Primavera após pasto $\left(\mathrm{Y}=0,201 \mathrm{X}+101,7 ; \mathrm{R}^{2}=0,92\right)$. Por outro lado, com a cultivar Canastra após soja, os resultados foram semelhantes aos encontrados para a cultivar BRSMG Conai, ou seja, obtiveram coeficiente de regressão negativo para número de grãos por panícula $\left(Y=-0,088 \mathrm{X}+99,3 ; \mathrm{R}^{2}\right.$ $=0,55)$. Isso ocorreu por causa da maior capacidade de perfilhamento da cultivar Canastra, que aumentou o número de panículas $\mathrm{m}^{-2}$ mesmo nas menores densidades.

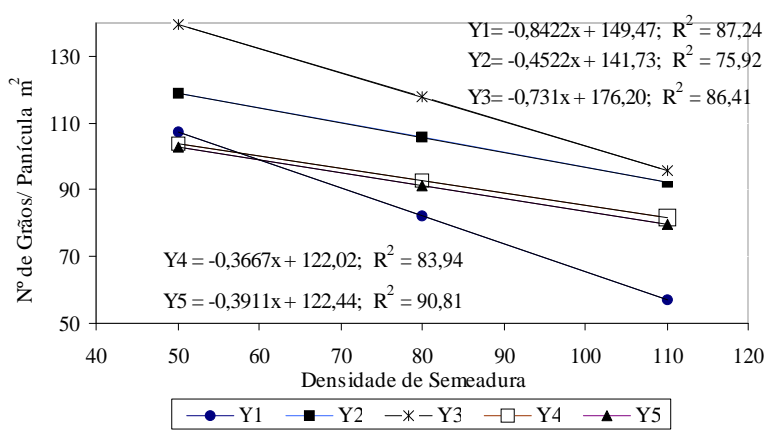

Figura 3 - Representação gráfica da equação de regressão, para número de grãos por panículas, em função de $\mathrm{D}: \mathrm{E}_{20} \mathrm{~A}_{1}$ (Y1); D: $E_{20} A_{2}(Y 2) ; D: E_{30} A_{2}(Y 3) ; D_{30} A_{3}$ (Y4) e D: $E_{40} A_{3}$ (Y5)

Pelo resultado da análise de variância conjunta para produtividade de grãos (Tabela 1) percebe-se significância para várias fontes de variação. Foi desdobrada apenas a interação tripla $\mathrm{E}^{*} \mathrm{D} * \mathrm{~A}$. No desdobramento de espaçamento dentro de densidade-ambiente (E:D-A), notou-se efeito de espaçamento para as três densidades $\left(50,80\right.$ e 110 sementes $\left.\mathrm{m}^{-1}\right)$, mas somente no ambiente 1 
(Tabela 4). A referida tabela, traz ainda as médias para espaçamentos (última linha) e densidade de semeadura (última coluna). Nota-se que o espaçamento que proporcionou a maior média de produtividade de grãos foi o de $30 \mathrm{~cm}$ entre linhas (mais de $11,1 \%$ em relação ao espaçamento de $40 \mathrm{~cm}$, independente da densidade). Resultados semelhantes, para produtividade de grãos, foram encontrados por Crusciol et al. (2003), Guimarães et al. (2003) e Santos et al. (2002). Os últimos, avaliaram seis cultivares lançadas pela Embrapa Arroz e Feijão, nos espaçamentos de 20, 30, 40 e $50 \mathrm{~cm}$ e todas elas maximizaram a produtividade no espaçamento de $30 \mathrm{~cm}$ entrelinhas. Os trabalhos de Santos \& Costa (1996), em Goiás, divergem quanto ao espaçamento que proporciona maior produtividade: encontraram para as cultivares Araguaia e Guarani, a máxima produtividade de grãos a 40 e $50 \mathrm{~cm}$ entrelinhas.

No desdobramento de D:E-A (Figura 4), houve significância em três níveis de E-A; o efeito de densidade produziu três equações lineares de regressão para a característica produtividade de grãos. Na equação linear Y1, a densidade influenciou negativamente a produtividade de grãos, à razão de $18,587 \mathrm{~kg} \mathrm{ha}^{-1}$ para cada semente que foi semeada além de $50 \mathrm{~m}^{-1}$. Porém, as equações lineares Y2 e Y3 mostraram relação linear e positiva de densidade com a produtividade de grãos, aumentando a razão de $18,31 \mathrm{~kg}$ ha $^{-1}$ e $18,02 \mathrm{~kg} \mathrm{ha}^{-1}$, para cada semente além de $50 \mathrm{~m}^{-1}$, respectivamente. Resultados diferentes foram obtidos por Santos et al. (2002) em Lavras, que verificaram, para as cultivares Canastra e Confiança, relação quadrática apesar das médias de produção em função da densidade de semeadura não diferirem estatisticamente entre si.

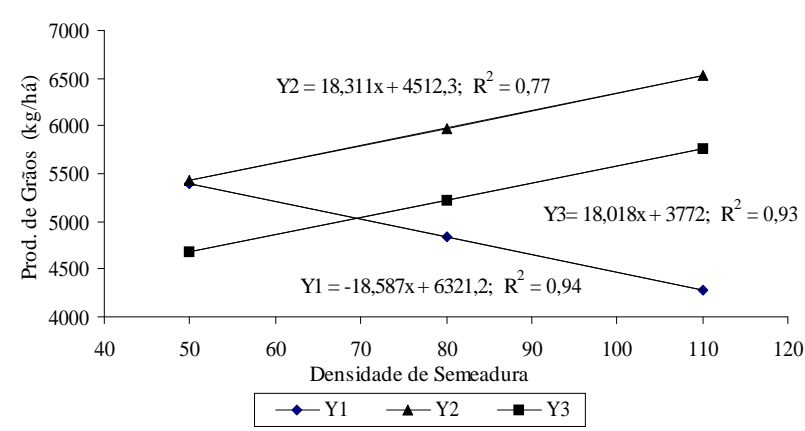

Figura 4 - Representação gráfica da equação de regressão, para produtividade de grãos em $\mathrm{kg} \mathrm{ha}^{-1}$, em função de D: $E_{20} A_{1}(Y 1), D: E_{30} A_{1}(Y 2)$ e D: $E_{40} A_{1}(Y 3)$.

\section{CONCLUSÕES}

As características como porcentagem de grãos cheios e massa de 100 grãos sofrem pequena ou nenhuma interferência do espaçamento, ao contrário do número de panículas $\mathrm{m}^{-2}$, número de grãos por panícula e produtividade de grãos.

A densidade de semeadura não influencia a característica porcentagem de grãos cheios por panícula, mas afeta o número de panículas $\mathrm{m}^{-2}$, número de grãos por panícula, massa de 100 grãos e produtividade de grãos.

Os componentes de produção de grãos mais influenciados pelos tratamentos espaçamento e densidade de semeadura são o número de panículas $\mathrm{m}^{-2}$ e número de grãos por panícula.

Para a cultivar BRSMG Conai, o espaçamento de 30 $\mathrm{cm}$ entrelinhas proporciona a maior produtividade de grãos, independente da densidade de semeadura. Contudo, a densidade de 80 sementes $\mathrm{m}^{-1}$ é a que mais contribuiu para a produtividade de grãos.

\section{REFERÊNCIAS BIBLIOGRÁFICAS}

ANTUNES, F. Z. Caracterização climática do Estado de Minas Gerais. Informe Agropecuário, Belo Horizonte, n. 138, p. 9-13, jul. 1986.

BRESEGHELLO, F. Semeadura do arroz. In: BRESEGHELLO, F.; STONE, L. F. (Eds.). Tecnologia para o arroz de terras altas. Santo Antônio de Goiás: Embrapa Arroz e Feijão, 1998. p. 55-58.

CRUSCIOL, C. A. C. et al. Produtividade do arroz de terras altas sob condições de sequeiro e irrigado por aspersão em função do espaçamento entre fileiras. Pesquisa Agropecuária Brasileira, Brasília, 2003. Disponível em: <http://www.crusciol@fea.unesp.br>. Acesso em: 12 ago. 2005.

FERREIRA, D. F. SISVAR - Sistema de Análise de Variância. Versão 4.6. Lavras: UFLA/DEX, 2003. Disponível em: <http://www.danielff@ufla.br>. Acesso em: 12 out. 2005.

GUIMARÃES, C. M.; STONE, L. F. Adubação nitrogenada do arroz de terras altas no sistema de plantio direto. Revista Brasileira de Engenharia Agrícola e Ambiental, Campina Grande, v. 7, n. 2, p. 210-214, maio 2003.

GUIMARÃES, C. M.; STONE, L. F.; SILVA, F. X. Espaçamento entre linhas para o arroz de terras altas com arquitetura de planta moderna. Santo Antônio de Goiás: Embrapa Arroz e Feijão, 2003. (Comunicado técnico, 67). 
SANTOS, A. B. dos; COSTA, J. D. Crescimento de arroz de sequeiro em diferentes populações e irrigação suplementar. 1996. Tese (Doutorado em Fitotecnia) - Escola Superior de Agricultura Luiz de Queiroz, Piracicaba, 1996.

SANTOS, P. G. et al. Efeito do espaçamento e densidade de semeadura sobre a produção de arroz de terras altas irrigado por aspersão. Ciência e Agrotecnologia, Lavras, v. 26, n. 3, p. 480-487, maio/jun. 2002.
SOARES, A. A. Cultura do arroz. Lavras: UFLA, 2001. v. 1, 114 p. (Textos acadêmicos, 7).

SOARES, A. A. Cultura do arroz. 2. ed. Lavras: UFLA/ FAEPE, 2005. 130 p. (Textos acadêmicos, 7).

YOSHIDA, S. Physiological aspects of grain yield. Annual Review of Plant Physiology, Palo Alto, v. 23, p. 437-464, 1972. 